\title{
Understanding the mental health burden of COVID-19 in the United Kingdom
}

\author{
Barbara Cristina da Silva Lopes \\ Universidade de Coimbra, Coimbra, Portugal \\ Rusi Jaspal \\ Nottingham Trent University, Nottingham, UK
}

\begin{abstract}
This article outlines the mental health burden of COVID-19 in the United Kingdom population, and presents preliminary evidence of less common psychiatric issues, such as paranoia and hallucinations, to which vulnerable groups in the UK population may be more vulnerable. It is argued that cognitive behavioural therapy, with components of mindfulness, should be part of the therapeutic response.
\end{abstract}

\section{Keywords}

COVID-19, social isolation, religious/ ethnic minorities, depression, paranoia

\section{Clinical Impact Statement}

The mental health burden of COVID-19 in the United Kingdom suggests that vulnerable groups in UK society, like students, employed people, religious/ethnic minorities and low income groups may be more prone to developing not only depression and anxiety disorders but symptoms of paranoia and hallucinations that are symptomatic of psychosis. Tailored Cognitive and Behavioral Therapy with components of Mindfulness and Coping Skills and Social Skills Training is recommended to ameliorate the negative and mental health burden of COVID-19 in the UK.

There is concern about the potential impact of COVID-19 on the onset of common mental health problems, such as depression and anxiety (Hyland et al., 2020; Kanter \& Manbeck, 2020; Shevlin et al., 2020; see Torales et al., 2020 for a review). More specifically, it is feared that self-isolation associated with social distancing measures introduced in the UK may lead to the onset of depression, stress and anxiety in vulnerable individuals (Kanter \& Manbeck, 2020). Indeed, past studies reveal a strong link between social distancing and loneliness and the presence of depression and of anxiety (see Holt-Lunstad et al., 2015 for a review; Santini et al., 2020) and this may be accentuated in the context of COVID-19. Previous research also has consistently uncovered a link between social isolation and a poor social network and the presence of less common psychiatric issues symptomatic of psychosis, such as paranoia and hallucinations (see Freeman et al., 2011; see Rocha et al., 2017 for a review). Moreover, there is evidence that people in the UK are engaging in irrational behaviours, such as compulsive buying as a coping mechanism in response to COVID-19 (Jaspal, Lopes \& Lopes, 2020b).

However, the assumed relationship between self-isolation and the onset of depression, anxiety and stress disorders in the context of COVID-19 is not as straightforward as this suggests. In two studies in the UK (Jaspal, Lopes \& Lopes, 2020; Lopes, Jaspal, \& Lopes, 2020), it has been found that self-isolation per se does not necessarily lead to the onset of depression but that perceiving COVID-19 symptomatology (e.g., dry cough, fever) and being exposed to news reporting about the pandemic do. This is in line with recent research that has found in a United Kingdom sample that those who perceived COVID-19 symptomatology were more at risk of depression and anxiety disorders (Shevlin et al., 2020). Moreover, this supports past 
research that has found that exposure to sensationalized media coverage of public health crises, such as the Ebola outbreak, led to depression and psychological distress even in people with no symptoms of the disease (Thompson et al., 2017). Furthermore, according to new research, decreased political trust, lacking a strong social network, and having fear of COVID-19 appear to be better predictors of the onset of depression and of compulsive buying in people who self-isolate in the United Kingdom (Jaspal, Lopes \& Lopes, 2020a, 2020b).

Often overlooked and marginalised groups in society are found in general to be more vulnerable than others to developing depression, anxiety and stress (Fitzpatrick, 1993; see Patel et al., 2018 for a review). In our studies, we have observed that low income groups may not possess the resources to help them deal with the challenges associated with COVID-19, such as sudden unemployment and financial difficulties, which may prompt their poor mental health (Hyland et al., 2020; Shevlin et al., 2020). Therefore, they may need to continue working despite the risks of infection and thus be at higher risk of developing depression, anxiety, stress disorders. Moreover, previous research in the UK also indicates that younger people (Hyland et al., 2020; Shevlin et al., 2020), students (Ellet, Lopes \& Chadwick, 2003) and people who are already diagnosed with a mental health disorder may also be at greater risk of developing mental health issues, including developing psychotic symptoms of paranoia and of hallucinations (Freeman et al., 2011). In support of this, we also found that students and younger people are more vulnerable to both paranoia and hallucinations in response to COVID-19 in the United Kingdom (Lopes, Bortolon \& Jaspal, 2020). Furthermore, existing evidence has shown that Muslim minorities appear to be at a greater risk of developing paranoia than the White non-religious majority in the US (see Rippy \& Newman, 2016) and this has also been observed in the United Kingdom in the context of the COVID-19 outbreak (Lopes et al., 2020b). This suggests that any recommendations provided to the general population should take into account age, occupation status and socio-economic and religious factors in order to achieve a better effect and reach.

Health professionals and researchers have focused on the impact of COVID19 on common mental health problems (see Holmes et al., 2020; Hyland et al., 2020; Shevlin et al., 2020; Torales et al., 2020), but less common conditions symptomatic of psychosis, such as paranoia and hallucinations, have largely been overlooked in commentaries and research (see Holmes et al., 2020; Hyland et al., 2020; Qiu et al., 2020; Shevlin et al., 2020; Torales et al., 2020). Paranoia has been defined in the clinical literature as a symptom of psychosis that is characterised by the idea that others are intentionally and maliciously trying to cause one harm and ranges from more usual fears (e.g., that others are talking negatively about one) to less common fears (e.g., being the victim of a conspiracy) (see Freeman et al., 2005). Moreover, paranoia and hallucinations (i.e. anomalous experiences like seeing and hearing things that are not there, see Morrison, Wells \& Nothard, 2000) are found to be interrelated and to be prompted by exposure to stress-inducing events (Freeman et al., 2011; Lincoln, Peter, Schäfer \& Moritz, 2008; Lopes \& Pinto-Gouveia, 2013). Paranoia has also been consistently related to discrimination and social disadvantage (Wickham et al., 2014), with ethnic minority groups (Quassem et al., 2015) and lower income individuals being more prone to developing psychosis (Madiha et al., 2016).

Although it is generally recognised that there is a continuum of paranoia and hallucinations between non-clinical and clinical populations (van Os et al., 2009), it is also acknowledged that exposure to highly threatening and fear-inducing events such as COVID-19 may lead to the onset of paranoia and hallucinations and, potentially, to the development of psychosis in vulnerable individuals (Freeman \& Freeman, 2008). For example, a case study has shown that Brexit, i.e., the United Kingdom's departure 
from the European Union, which was construed by some as a politically destabilising and unsettling event, induced a transient psychotic disorder characterised by the presence of both paranoia and hallucinations in an individual with no history of mental health issues or neurological problems (Katshu, 2019). Moreover, in support of previous research, our research shows that certain groups in British society are more vulnerable to developing paranoia against the backdrop of COVID-19, namely religious minorities and people with another diagnosed mental health disorder, such as depression (Lopes, Bortolon \& Jaspal, 2020).

In support of the vulnerability x stress model for paranoia (see Freeman et al., 2011; Wickham et al., 2014), paranoia and hallucinations appear to be related to decreased political trust, to the absence of a strong social network and to perceived COVID-19 symptomatology (Lopes, Bortolon \& Jaspal, 2020). Moreover, those with paranoia and hallucinations are more likely to engage in the maladaptive coping behaviour of compulsive buying which may sustain the paranoid thoughts and associated mistrust in political institutions (Lopes et al., 2020). It is easy to see how vulnerable groups, such as those with a mental health disorder and religious minorities, may be suspicious of their own government, lack social support and potentially develop psychotic symptoms.

It is vital for healthcare services to prepare for a possible rise in mental health problems in the population in the aftermath of COVID-19 (see Holmes et al., 2020). Existing resources will be valuable, including the digitised Computerized Cognitive and Behavioural Therapy (CBT) at Step 2 in the National Health Service (NHS) in the UK, which would benefit from some adaptation to the specific stressors associated with COVID-19. This tailored digital CBT may include components of mindfulness, be provided online, and have clinical psychologists and/or CBT therapists on call to address emerging challenges. The digital CBT must include components of stress management and the management of worry and fear as well as components of CBT oriented to managing distressing voices and paranoid thoughts in the context of COVID-19 (e.g., sudden unemployment, sudden social isolation, death, etc.). Indeed, it is well documented in the literature that CBT- and mindfulness-based therapies, such as compassionate mind-focused therapy, are highly effective in treating people with depression and paranoia and hallucinations (Braehler et al., 2012; Chadwick et al., 2016; Freeman et al., 2015; Key, Craske \& Reno, 2003). However, these approaches must be tailored to the context of COVID-19 and must include coping skills and social skills training to address issues that are especially likely to affect particular high-risk groups (e.g., how to cope with discrimination and sudden unemployment) (Kompus, 2018). It is essential to begin to address the emerging mental health burden of COVID-19 which will remain once the pandemic is over.

\section{References}

Braehler, C., Gumley, A., Harper, Wallace, S., Norrie, J. \& Gilbert, P. (2012) Exploring change processes in compassion focused therapy in psychosis: Results of a feasibility randomized controlled trial. British Journal of Clinical Psychology, 52 (2), 199-214. doi: 10.1111/bjc.12009.

Chadwick, P., Strauss, C., Jones, A., Kingdon, D., Ellett, L., Dannahy, L. \& Hayward, M. (2016) Group mindfulness-based intervention for distressing voices: A pragmatic randomised controlled trial. Schizophrenia Research, 175, 168-203. doi: 10.1016/j.schres.2016.04.001 
Ellett, L., Lopes, B., \& Chadwick, P. (2003). Paranoia in a nonclinical population of college students. Journal of Nervous and Mental Disease, 191, 425-430. https://doi.org/10.1097/01.NMD.0000081646.33030.EF

Fitzpatrick, K. M. (1993). Exposure to violence and presence of depression among lowincome, African-American youth. Journal of Consulting and Clinical Psychology, 61(3), 528-531. https://doi.org/10.1037/0022-006X.61.3.528

Freeman, D., Garety, P.A., Bebbington, P.E., Smith, B., Rollinson, R., Fowler, D., Kuipers, E., Katarzyna, R. \& Dunn, G. (2005). Psychological investigation of the structure of paranoia in a non-clinical population. British Journal of Psychiatry, 186, 427-435. DOI:10.1192/bjp.186.5.427

Freeman, D \& Freeman J. (2008) Paranoia: the 21 $1^{\text {st }}$ Century Fear. Oxford, Oxford University Press, United Kingdom

Freeman, D., McManus, S., Brugha, T., Meltzer, H., Jenkins, R., \& Bebbington, P. (2011). Concomitants of paranoia in the general population. Psychological Medicine, 41, 923-936. https://doi.org/10.1017/S0033291710001546

Freeman, D., Dunn, G., Startup, H., Pugh, K., Cordwell, J., Mander, H., Cernis, E., Wingham, G., Shrivell, K. \& Kingdon, D. (2015) Effects of cognitive behaviour therapy for worry and persecutory delusions in patients with psychosis (WIT): a parallel, singleblind, randomised controlled trial with a mediation analysis. Lancet Psychiatry, 2 (4), P305-313. DOI: https://doi.org/10.1016/S2215-0366(15)00039-5

Holmes, E., O’Connor, R., Perry, H., Tracey, I., Wessely, S., Arseneault, L., Ballard, C., Christensen, E., Silver, R., Everall, I., Ford, T., John, A., Kabir, T., King, K., Madan, I., Michie, S., Przybylski, A., Shafran, R., Sweeney, A., Worthman, C., Yardley, L., Cowan, K., Cope, C., Hotopf, M. \& Bullmore, E. (2020) Multidisciplinary research priorities for COVID-19 pandemic: a call for action for mental health science. Lancet Psychiatry. Position Paper, 1-14. DOI: https://doi.org/10.1016/S2215-0366(20)301681

Holt-Lunstad, J., Smith, T. B., Baker, M., Harris, T., \& Stephenson, D. (2015) Loneliness and social isolation as risk factors for mortality: a meta-analytical review. Perspectives on Psychological Science, 10 (2), 227-237. doi: $10.1177 / 1745691614568352$.

Hyland, P., Shevlin, M., McBride, O., Murphy, J., Karatzias, T., Bentall, R., Martinez, A. \& Vallières, F. (2020) Anxiety and depression in the Republic of Ireland during the COVID-19 pandemic. Preprint. DOI: 10.31234/osf.io/8yqxr

Jaspal, R., Lopes, B. \& Lopes, P. (2020a) Fear, Social isolation in response to Covid19 in a religiously diverse UK sample. Under review.

Jaspal, R., Lopes, B. \& Lopes, P. (2020b) Predicting social distancing and compulsive behaviours in response to Covid-19 in a UK sample. Under review.

Kanter, J. \& Manbeck, C. (2020) Covid-19 could lead to an epidemic of clinical depression, and the health care system is not ready for that either. Retrieved from the 
Conversation on the $12^{\text {th }}$ of April 2020: https://theconversation.com/covid-19-couldlead-to-an-epidemic-of-clinical-depression-and-the-health-care-system-isnt-ready-forthat-either-134528

Katshu, M.Z.U.H. (2019) Acute transient psychotic disorder precipitated by Brexit vote. British Medical Journal Case Report, 12:e232363. doi:10.1136/bcr-2019-232363

Key, F., Craske, M. \& Reno, R. (2003) Anxiety-based cognitive-behavioral therapy for paranoid beliefs. Behavior Therapy, 34 (1), 97-115. https://doi.org/10.1016/S00057894(03)80024-2

Kompus, K. (2018) Virtual Reality CBT helps reduce paranoia, anxiety in psychotic disorders. Lancet Psychiatry, 5 (3), 189-191. doi:10.1016/S2215-0366(18)30063-4.

Lincoln, T., Peter, N., Schäfer, M. \& Moritz, S. (2008) Impact of stress on paranoia: an experimental investigation of moderators and mediators. Psychological Medicine, 39 (7) 1129-1139. doi:10.1017/S0033291708004613

Lopes, B. \& Pinto-Gouveia, J. (2013) The role of predisposition to hallucinations on non-clinical paranoid vs. socially anxious individuals after hearing negative affectladen sounds: an experimental investigation. Behavioural and Cognitive Psychotherapy, 41, 221-237.doi:10.1017/S1352465812000483

Lopes, B., Jaspal, R., \& Lopes, P. (2020) Impact of COVID-19 news on depression: a preliminary experimental Study. Under review.

Lopes, B., Bortolon, C. \& Jaspal, R. (2020) Paranoia, hallucinations and compulsive buying in respose to COVID-19 in a UK sample: a preliminary experimental study. Under review.

Madiha, S., Ellett, L., Dutt, A., Day, F., Laing, J., Kroll, J., Petrella, S., McGuire, P. \& Valmaggia, L. (2016) Perceived ethnic discrimination and persecutory paranoia in individuals at ultra-risk for psychosis. Psychiatry Research, 241, 309-3014. DOI: https://www.sciencedirect.com/science/article/abs/pii/S0165178115304819

Morrison, A. P., Wells, A. \& Nothard, S. (2000). Cognitive factors in the predisposition to auditory and visual hallucinations. British Journal of Clinical Psychology, 39, 6778.DOI: $10.1348 / 014466500163112$

Patel, V., Burns, J., Dhingra, M., Tarver, L., Kohrt, B. \& Lund, C. (2018) Income inequality and depression: a systematic review and meta-analysis of the association and a scoping review of mechanisms. World Psychiatry, 17 (1), 76-89. doi: $10.1002 /$ wps. 20492

Qiu, J., Shen, B., Zhao, M., Wang, Z., Xie, B. \& Yifeng, X. (2020) A nationwide survey of psychological distress among Chinese people in the COVID-19 epidemic: implications and policy recommendations. General Psychiatry, 33: e1002013. doi:10.1136/gpsych-2020-100213

Quassem, T., Bebbington, P., Spiers, N., McMannus, S., Jenkins, R., Dein, S. (2015) Prevalence of psychosis in Black ethnic minorities in Britain: analysis based on three 
national surveys. Social Psychiatry and Psychiatric Epidemiology, 50, 1057-1064. https://doi.org/10.1007/s00127-014-0960-7

Rippy, A. E., \& Newman, E. (2006). Perceived religious discrimination and its relationship to anxiety and paranoia among Muslim Americans. Journal of Muslim Mental Health, 1(1), 5-20. https://doi.org/10.1080/15564900600654351

Rocha, B.M., Rhodes, S., Vasilopoulou, E. \& Hutton, P. (2018) Loneliness in Psychosis: A Meta-analytical Review. Schizophrenia Bulletin, 44 (1), 114-125. doi:10.1093/schbul/sbx036

Santini, Z., Jose, P., Cornwell, E., Koyanagi, A., Nielsen, L., Hinrichsen, C., Meilstrup, C., Madsen, K., Koushede, V. (2020) Social disconnectedness, perceived isolation, and symptoms of depression and anxiety among older Americans (NSHAP): a longitudinal mediation analysis. Lancet Public Health, 5, e62-e70. https://doi.org/10.106/S24682667(19)30230-0

Shevlin, M., McBride, O., Murphy, J., Miller-Gibson, J., Hartman, T., Levita, L., Mason, L., Martinez, A., McKay, R., Stocks, T., Bennett, K., Hyland, P., Karatzias, T. \& Bentall, R. (2020) Anxiety, Depression, Traumatic Stress, and COVID-19 related Anxiety in the UK General Population During the COVID-19 Pandemic. Pre-print. DOI:10.31234/osf.io/hb6nq

Thompson, R., Garfin, D., Holman, E. A. \& Silver, R. (2017) Distress, Worry, and Funtioning Following a Global Health Crisis: A National Study on the Americans' Responses to Ebola. Clinical Psychological Science, 5 (3), 513-521. https://doi.org/10.1177/21677026176920

Torales, J., O’Higgins, M., Castaldelli-Maia, J. \& Ventriglio, A., (2020) The outbreak of COVID-19 coronavirus and its impact on global mental health. International Journal of Social Psychiatry, 31, 1-4. https://doi.org/10.1177/0020764020915212

van os, J., Linscott, R.J., Myin-Germeys, I., Delespaul, P., Krabbendaum, L. (2009) A systematic review and meta-analysis of the psychosis continuum: evidence for psychosis-proneness-persistence-impairment model of psychotic disorder. Psychological Medicine, 39 (2), 179-95.doi: 10.1017/S0033291708003814

Wickham, S., Taylor, P., Shevlin, M. \& Bentall, R. (2014) The Impact of Social Deprivation on Paranoia, Hallucinations, Mania and Depression: The Role of Discrimination, Social Support, Stress and Trust. PLoS One, 9 (8) e105140. doi: 10.1371/journal.pone.0105140. 